\title{
TRACEABLE CALIBRATION OF PRESSURE BASED WATER LEVEL DATA LOGGERS
}

\author{
L. Grgec Bermanec ${ }^{1,2}$, I. Matas ${ }^{1,3}$, D. Zvizdić ${ }^{1,4}$ \\ ${ }^{1}$ University of Zagreb, Faculty of Mechanical Engineering and Naval Architecture, Laboratory for Process \\ Measurement, Zagreb, Croatia, ${ }^{2}$ lovorka.grgec@fsb.hr, ${ }^{3}$ ivan.matas@fsb.hr, ${ }^{4}$ davor.zvizdic@fsb.hr
}

\begin{abstract}
:
This paper investigates accuracy, influence of temperature variations and time drift of water level data loggers, operating on a principle of hydrostatic pressure measurement. The laboratory setup for calibration of such devices, equipped with selfdesigned pressure chamber and commercial climatic chamber is presented. Calibration procedure for logger's built-in pressure transducer, with ensured traceability to the primary standards of pressure and temperature, is proposed. Influence of temperature on the pressure reading was examined by conducting calibration at $10^{\circ} \mathrm{C}, 15^{\circ} \mathrm{C}$ and $25^{\circ} \mathrm{C}$.
\end{abstract}

Keywords: water level data logger; pressure; calibration setup; traceability

\section{INTRODUCTION}

Demand for monitoring of groundwater and surface water levels is growing in oceanology, hydrology, water resource management and many other fields. Water level data loggers are mostly used for investigation of water resources such as lakes, tidal areas or wells. Scarcity of drinking water emphasizes the need for accurate groundwater level reading. Also, ongoing climate changes cause water level increase, due to melting of ice caps, which confirms the importance of precise water level monitoring. In order to provide accurate water level reading, hydrostatic pressure has to be measured correctly and ambient temperature has to be monitored. Built-in absolute pressure sensors should be calibrated against traceable pressure standards. However, industry-wide standardized method for that is lacking[1]. This paper provides the calibration setup for pressure transducer, incorporated into the water level logger that cannot be directly connected to pressure system and examines the dependency of the pressure reading on the temperature of the surrounding medium.

\section{METHODS}

Many commercially available water level data loggers that operate on principle of hydrostatic pressure measurement, have built-in piezoresistive pressure transducer as a measuring unit. Such sensors, exhibit high sensitivity but have significant temperature dependency of pressure reading[2]. Different techniques for temperature compensation of piezoresistive sensor can be found in the literature[3],[4]. This influence of temperature should also be taken into account when evaluating measurement uncertainty of calibration. Therefore, the calibration setup was placed inside the climatic chamber, allowing the examination of temperature dependency of the calibrated logger to be done as well.

In this study, a commercial water level data logger with operating range between 0 and 9 meters of water depth, was used. Pressure measuring range of its built-in piezoresistive sensor is between 0 and 2000 mbar absolute. As it is mostly used for measuring water depth at sea level, the calibration range was decided to be from 1000 to 2000 mbar absolute. The calibration was performed at 10,15 and $25^{\circ} \mathrm{C}$, since the logger is mostly used at that temperature range.

\subsection{Calibration setup}

Since the logger cannot be directly connected to pressure system, it was necessary to design and produce a pressure chamber (Figure 1) that can withstand a pressure up to 2500 mbar.

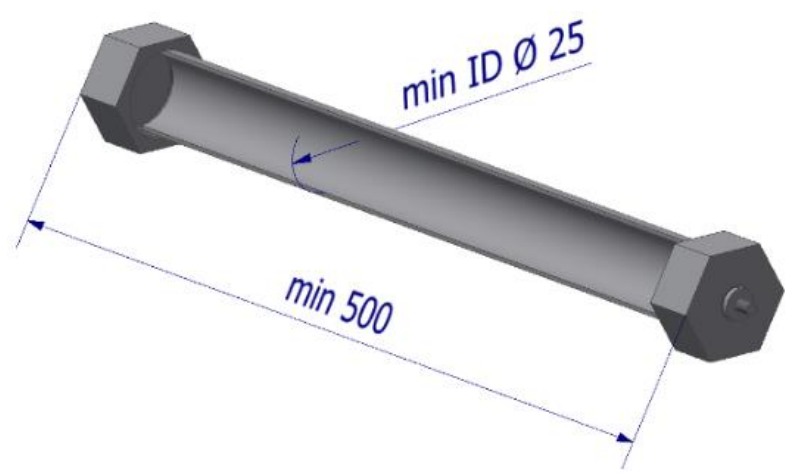

Figure 1: Pressure chamber 
Other construction demands were that it could accommodate up to three loggers $(\mathrm{L}=150 \mathrm{~mm}, \varnothing 25$ $\mathrm{mm})$ at the same time and fit into the climatic chamber (Figure 2) so that the calibration could be performed under different temperatures. Also, the volume of the chamber, should be as small as possible to minimize pressure fluctuations and time for stabilization. The trade-off had to be made between number of loggers, that can be calibrated at once, and time for stabilization of conditions (pressure and temperature) inside the chamber.

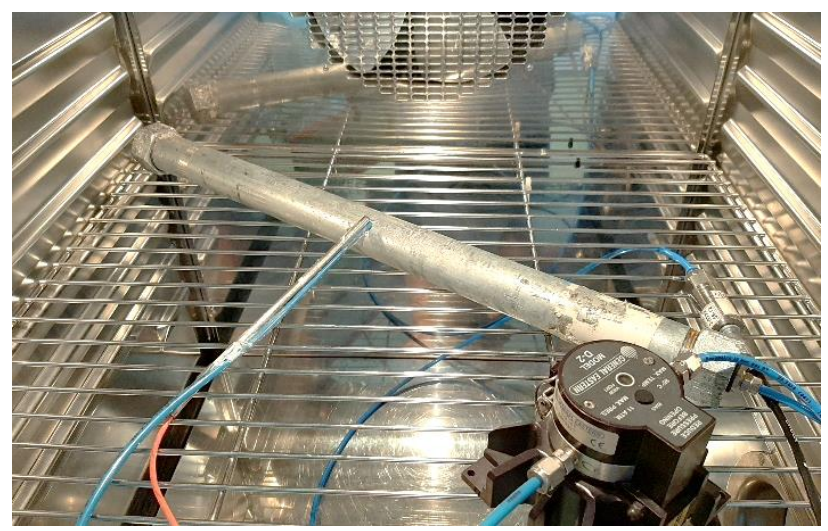

Figure 2: Pressure chamber inside the climatic chamber

Pressure chamber was constructed from zinc coated pipe and two threaded cast iron caps, one having a standardised pressure inlet, for the connection to the pressure system. Threads were properly sealed, and a leak test was conducted, prior to calibration. As no leakage occurred at maximum pressure, chamber showed appropriateness to be used as mean for calibration of water level data logger.

The calibration setup (Figure 3 and Figure 3) consisted of pressure chamber, climatic chamber, pressure standard, in form of pressure transducer (with operating range of 0 mbar to $1000 \mathrm{mbar}$ gauge) connected to pressure calibrator (indication), barometric pressure logger and standard platinum resistance thermometer (Pt-100). All of the equipment was calibrated prior to setup, with ensured traceability as Laboratory for Process Measurement is national standard laboratory for pressure, temperature and humidity.

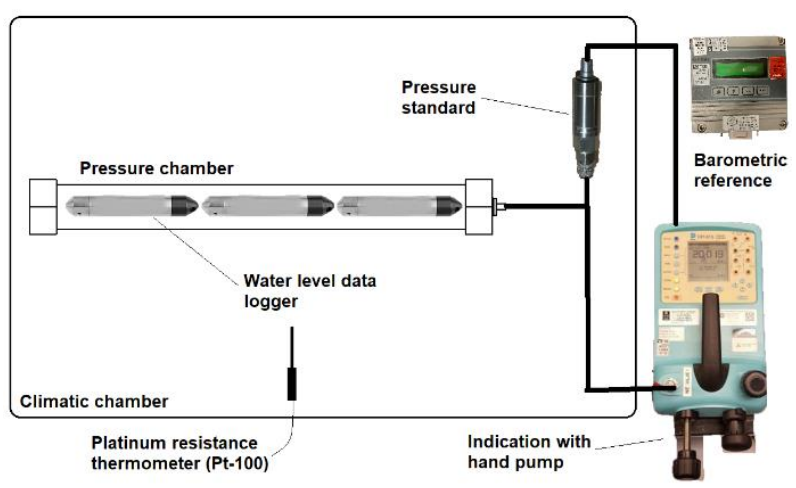

Figure 3: Calibration setup - scheme

\subsection{Calibration procedure}

The calibration procedure was built upon standardised procedures and included 11 pressure points $(0,100,200,300,400,500,600,700,800,900$, 1000 mbar gauge) in three sequences (two increasing and one decreasing)[5]. Barometric pressure was measured with reference barometer in every calibration point. Temperature was monitored with standard platinum resistance thermometer (Pt-100) and logger's built-in temperature sensor (thermistor).

To ensure traceability, pressure transducer was first calibrated against gas pressure balance, characterized in [6] and then connected to pressure system. After the ambient temperature in the climatic chamber has stabilized, for every measurement point, the procedure was following. Pressure was generated in the system using a hand pump. After achieving and stabilization of the desirable pressure point on the standard, water level logger recorded three pressure readings and the barometric pressure was manually logged. After completing all three calibrations, readout of the logger was performed with its software. Water level data is calculated from the pressure readings when the input of fluid density and barometric reference is given.

\section{RESULTS AND MESUREMENT UNCERTAINTY EVALUATION}

After analysis of raw data and determination of measurement uncertainty, the results showed that logger did exhibit certain change in pressure reading due to change of temperature. At $15{ }^{\circ} \mathrm{C}$ deviation from the pressure standard was the lowest of all temperatures, with the maximum absolute value of 0.9 mbar. A slight increase of deviation occurred at $25^{\circ} \mathrm{C}$, as seen from the Figure 4. Maximum deviation from the standard at $25^{\circ} \mathrm{C}$ was 1.2 mbar. In both cases deviation stayed within raw pressure measurement accuracy stated in the logger's calibration certificate $(0.3 \%$ FS or 6.3 mbar).

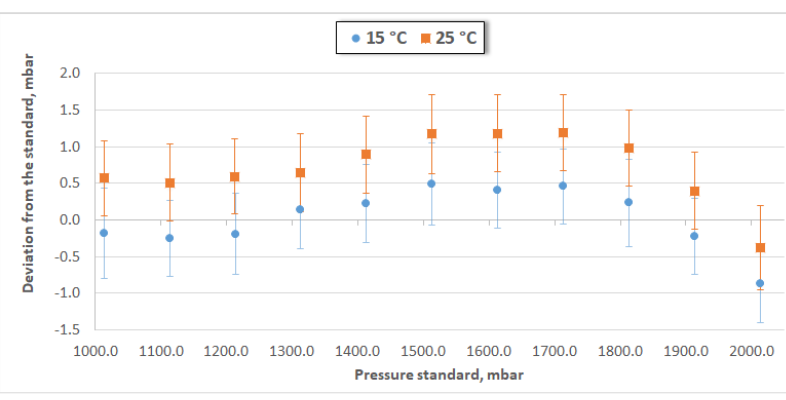

Figure 4: Deviation from the pressure standard at $15^{\circ} \mathrm{C}$ and $25^{\circ} \mathrm{C}$

At $10{ }^{\circ} \mathrm{C}$ logger exceeded accuracy limits (dashed lines) as can be seen from Figure 5. The measurement uncertainty was also significantly greater than at $15^{\circ} \mathrm{C}$ and $25^{\circ} \mathrm{C}$, due to contribution of repeatability and hysteresis. Deviations of the logger's reading 
with associated measurement uncertainties are shown in Table 2 .

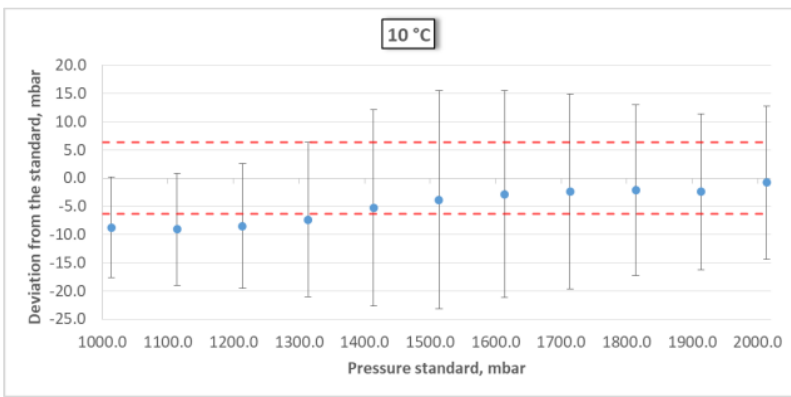

Figure 5: Deviation from the pressure standard at $10{ }^{\circ} \mathrm{C}$

Logger's built-in thermistor indicated deviation from the platinum resistance thermometer. Greatest deviation, close to $0.4{ }^{\circ} \mathrm{C}$ occurred at lowest temperature, and decreased towards the highest temperature point, as can be seen from Table 1. Main contribution to the temperature measurement uncertainty is from the temperature gradients in the climatic chamber.

Table 1: Comparison of temperature readings

\begin{tabular}{|c|c|c|}
\hline $\begin{array}{c}\text { Temperature } \\
\text { standard } \\
(\mathbf{P t}-100)\end{array}{ }^{\circ} \mathbf{C}$ & $\begin{array}{c}\text { Temperature } \\
\text { measured by }^{\text {bogger, }}{ }^{\circ} \mathbf{C}\end{array}$ & $\begin{array}{c}\text { Measurement } \\
\text { uncertainty } \\
\boldsymbol{k}=\mathbf{2},{ }^{\circ} \mathbf{C}\end{array}$ \\
\hline 10.31 & 10.7 & 2.00 \\
\hline 15.15 & 15.3 & 2.00 \\
\hline 25.15 & 25.1 & 2.00 \\
\hline
\end{tabular}

\section{DISCUSSION}

The results at $15{ }^{\circ} \mathrm{C}$ and $25{ }^{\circ} \mathrm{C}$ indicated the deviation of logger's pressure reading with temperature, although its calibration certificate states complete temperature compensation in the range from $0{ }^{\circ} \mathrm{C}$ to $40{ }^{\circ} \mathrm{C}$. This confirmed the need for examination of temperature dependency of piezoresistive transducers prior to calibration.
At $10{ }^{\circ} \mathrm{C}$, logger's reading did not show congruency with results at $15^{\circ} \mathrm{C}$ and $25^{\circ} \mathrm{C}$. This can be attributed to sudden temperature change from room temperature with not enough time for stabilization. According to manufacturer, sudden temperature changes should be avoided. Also, lower operating limit of climatic chamber is $10{ }^{\circ} \mathrm{C}$, so the stabilization of temperature in the climatic, as well as in pressure chamber is much longer at that temperature. Thus, large discrepancy between results at $10{ }^{\circ} \mathrm{C}$ and at other two temperatures, can be attributed to unsteady thermal conditions during measurements. This emphasized the importance thermal stability before calibration of such devices, for conducting low uncertainty measurements. These results were not considered for further uncertainty evaluation.

From the measurements at $15{ }^{\circ} \mathrm{C}$ and $25{ }^{\circ} \mathrm{C}$, contribution of temperature dependency of pressure reading to measurement uncertainty can be calculated. Largest difference between deviation at $15^{\circ} \mathrm{C}$ and at $25{ }^{\circ} \mathrm{C}$ was taken as the maximum value of error due to influence of temperature on the pressure sensor. Example of measurement uncertainty budget, built upon[5], for further calibrations of such loggers using the presented laboratory setup is shown in Table 3. It is visible that, after the uncertainty of pressure standard, temperature influence on the pressure reading makes second largest contribution to the overall calibration uncertainty.

The proposal for examination of temperature influence on pressure reading would be to check the deviation in just few calibration points (eq. lowest, middle and highest pressure), at lowest and highest operating temperature of logger. From that data, influence of the temperature on the given logger can be estimated, without the conduction of the complete calibration procedure at two temperatures.

Table 2: Deviation of the logger from pressure standard

\begin{tabular}{|c|c|c|c|c|c|c|}
\hline \multirow{2}{*}{$\begin{array}{c}\text { Applied } \\
\text { pressure, } \\
\text { mbar }\end{array}$} & \multicolumn{2}{|c|}{ at $\mathbf{1 0}{ }^{\circ} \mathbf{C}$} & \multicolumn{2}{c|}{ at 15 ${ }^{\circ} \mathbf{C}$} & \multicolumn{2}{c|}{ at 25 ${ }^{\circ}$} \\
\cline { 2 - 7 } & $\begin{array}{c}\text { Deviation, } \\
\text { mbar }\end{array}$ & $\begin{array}{c}\boldsymbol{U}(\boldsymbol{k}=\mathbf{2}), \\
\text { mbar }\end{array}$ & $\begin{array}{c}\text { Deviation, } \\
\text { mbar }\end{array}$ & $\begin{array}{c}\boldsymbol{U}(\boldsymbol{k}=\mathbf{2}), \\
\text { mbar }\end{array}$ & $\begin{array}{c}\text { Deviation, } \\
\text { mbar }\end{array}$ & $\begin{array}{c}\boldsymbol{U}(\boldsymbol{k}=\mathbf{2}), \\
\mathbf{m b a r}\end{array}$ \\
\hline 1000.0 & -8.7 & 8.92 & -0.2 & 0.61 & 0.6 & 0.51 \\
\hline 1100.0 & -9.1 & 9.91 & -0.3 & 0.51 & 0.5 & 0.52 \\
\hline 1200.0 & -8.5 & 11.02 & -0.2 & 0.55 & 0.6 & 0.51 \\
\hline 1300.0 & -7.4 & 13.67 & 0.1 & 0.52 & 0.6 & 0.53 \\
\hline 1400.0 & -5.3 & 17.44 & 0.2 & 0.53 & 0.9 & 0.52 \\
\hline 1500.0 & -3.8 & 19.35 & 0.5 & 0.56 & 1.2 & 0.53 \\
\hline 1600.0 & -2.8 & 18.37 & 0.4 & 0.52 & 1.2 & 0.52 \\
\hline 1700.0 & -2.4 & 17.22 & 0.5 & 0.51 & 1.2 & 0.52 \\
\hline 1800.0 & -2.1 & 15.12 & 0.2 & 0.59 & 1.0 & 0.52 \\
\hline 1900.0 & -2.4 & 13.80 & -0.2 & 0.52 & 0.4 & 0.53 \\
\hline 2000.0 & -0.8 & 13.57 & -0.9 & 0.53 & -0.4 & 0.57 \\
\hline
\end{tabular}


Table 3: Uncertainty budget for calibration of water level data logger at pressure of 1200 mbar absolute

\begin{tabular}{|c|c|c|c|c|c|c|}
\hline Influence quantity & $\begin{array}{c}\text { Estimate, } \\
\text { mbar }\end{array}$ & $\begin{array}{c}\text { Variability } \\
\text { interval } \\
\mathbf{( 2} \mathbf{a}) \mathbf{m b a r}\end{array}$ & $\begin{array}{c}\text { Probability } \\
\text { distribution }\end{array}$ & Divisor & $\begin{array}{c}\text { Sensitivity } \\
\text { coefficient }\end{array}$ & $\begin{array}{c}\text { Contribution to } \\
\text { the standard } \\
\text { uncertainty, } \\
\text { mbar }\end{array}$ \\
\hline Pressure standard & 200.0 & 0.500 & normal & 2 & 1 & 0.06250 \\
\hline Barometric reference & 1013.1 & 0.086 & normal & 2 & 1 & 0.00185 \\
\hline Resolution & 0 & 0.1 & rectangular & $\sqrt{3}$ & 1 & 0.00083 \\
\hline Hysteresis & 0 & 0.3 & rectangular & $\sqrt{3}$ & 1 & 0.00926 \\
\hline Repeatability & 0 & 0.2 & rectangular & $\sqrt{3}$ & 1 & 0.00232 \\
\hline Temperature & 0 & 0.8 & rectangular & $\sqrt{3}$ & 1 & 0.05333 \\
\hline
\end{tabular}

\section{CONCLUSION}

Calibration setup and procedure for calibration of water level data loggers with built-in hydrostatic pressure sensor was presented. Calibration procedure is based on standardised calibration methods for pressure gauges. The laboratory calibration setup is additionally equipped with self-designed pressure chamber and therefore suitable for devices that cannot be directly connected to pressure system. By placing the whole setup inside the climatic chamber, the presented setup can be used for evaluation of temperature effect on pressure reading. Traceability of calibration is ensured to the primary standards of pressure and temperature, as the Laboratory for Process Measurement is holder of national standards of respected quantities.

The results of calibration at different temperatures showed increase in deviation from the standard due to increase of temperature for the tested logger, which confirmed the need for examination of temperature influence. Also, sudden temperature changes can lead to instability of pressure reading, so stable thermal conditions should be achieved prior to calibration. Uncertainty budget for future calibration of water level data loggers, that includes temperature influence on pressure reading, is proposed. The presented setup and procedure have shown applicability as standardised method for calibration of water level data loggers.

\section{ACKNOWLEDGEMENT}

The authors would like to thank company D.I.I.V. Ltd. and its chairman Donat Petricioli for provision of the water level data loggers for the purpose of this research.

\section{REFERENCES}

[1] J. P. R. Sorensen and A. S. Butcher, "Water Level Monitoring Pressure TransducersuA Need for Industry-Wide Standards," Ground Water Monitoring and Remediation, vol. 31, no. 4, pp. 5662, 2011, doi: 10.1111/j.1745-6592.2011.01346.x.

[2] S. S. Kumar and B. D. Pant, "Design principles and considerations for the 'ideal' silicon piezoresistive pressure sensor: A focused review," Microsystem Technologies, 2014, doi: 10.1007/s00542-014-22157.

[3] F. Reverter, G. Horak, V. Bilas, and M. Gasulla, "Novel and low-cost temperature compensation technique for piezoresistive pressure sensors," in 19th IMEKO World Congress 2009, 2009.

[4] M. Aryafar, M. Hamedi, and M. M. Ganjeh, "A novel temperature compensated piezoresistive pressure sensor," Measurement: Journal of the International Measurement Confederation, 2015, doi: 10.1016/j.measurement.2014.11.032.

[5] N. M. Aykurt Altintas, Wladimir Sabuga, Oliver Ott, Yasin Durgut, Pierre Otal, Janez Šetina, "Guidelines on the Calibration of Electromechanical and Mechanical Manometers Guidelines on the Calibration of Electromechanical and Mechanical Manometers," vol. 0, no. 17. Euramet e.V., 2019.

[6] L. Grgec Bermanec, M. Katic, and D. Zvizdic, "Characterization of gas pressure balances at LPM," Measurement: Journal of the International Measurement Confederation, 2019, doi: 10.1016/j.measurement.2018.10.070. 